\title{
Scleroderma, primary biliary cirrhosis, and Sjögren's syndrome after cosmetic breast augmentation with silicone injection: a case report of possible human adjuvant disease
}

\author{
Y. OKANO, M. NISHIKAI, AND A. SATO \\ From the Rheumatology Section, Department of Internal Medicine, the Second Tokyo National Hospital, \\ Tokyo, Japan
}

SUMMARY A 52-year-old woman developed scleroderma, primary biliary cirrhosis, and Sjögren's syndrome after cosmetic silicone injections. These conditions may possibly represent 'human adjuvant disease'.

A 52-year-old Japanese woman underwent breast augmentation with silicone injections in 1958. Thereafter she was in good health until 1974, when she developed a dry mouth (Fig. 1). Three years later she developed swollen stiff fingers and polyarthralgia. After that she had Raynaud's phenomenon in winter. In 1979, when she visited the Second Tokyo National Hospital, she had persistent polyarthralgia and proximal scleroderma.

Hard masses were palpable beneath the breast skin. Moist rales were audible over the lower lung fields bilaterally. Her liver was enlarged and felt firm. The skin over the fingers, forearms, and face was tight, thickened, and pigmented.

Laboratory tests showed total serum bilirubin 1.0 $\mathrm{mg} / \mathrm{dl}(17 \mu \mathrm{mol} / \mathrm{l})$, serum glutamic pyruvic transaminase (SGPT) 86 Karmen units, serum alkaline phosphatase 57.9 King-Armstrong units, HB virus antigen and antibody negative, rheumatoid factor positive (RAHA 1:256), LE cells negative, antinuclear antibody positive $(1: 80)$, anti-DNA antibody negative, antimitochondrial antibody positive (1:320), anti-smooth muscle antibody negative. Tests for precipitating antibodies were as follows: anti-nRNP antibody positive, anti-Scl-1 antibody positive, anti-La/SSB antibody negative, antiRo/SSA antibody negative, anti-Ku antibody nega-

Accepted for publication 21 November 1983.

Correspondence to M. Nishikai, MD, Rheumatology Section, Department of Internal Medicine, Second Tokyo National Hospital, 2-5-1 Higashigaoka, Meguroku, Tokyo, Japan 152. tive, anticentromere antibody negative. HLA typing was A2, 24, B52, 60, C3,-, DR2, 9, MT1, 3, 4. The chest roentgenogram showed a reticular pattern with linear and nodular densities in the lower third of the lung fields bilaterally. A barium swallow showed hypomotility and marked dilatation of the lower portion of the oesophagus. Pulmonary function tests showed decreased diffusing capacity (\% DLco 43\%). The results of some studies for sicca symptoms were as follows: Schirmer test right $0 \mathrm{~mm}$, left $0 \mathrm{~mm}$, fluorotest positive, Rose-bengal test positive. Sialography showed an 'apple-tree'-like appearance. Biopsy of a minor salivary gland showed periglandular fibrosis. Skin biopsy from the forearm showed marked thickening of the subcutaneous tissue due to proliferation of dense collagenous connective tissue

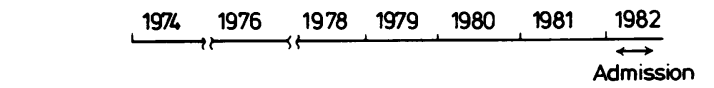

Dry mouth

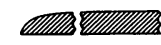

Tight skin

Raynaud's phenomenon

Arthralgia

Dyspnoea

Liver dysfunction

Jaundice

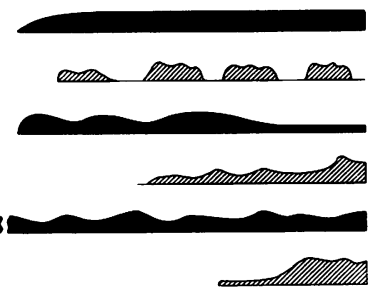

Fig. 1 Clinical course (1974-82). 


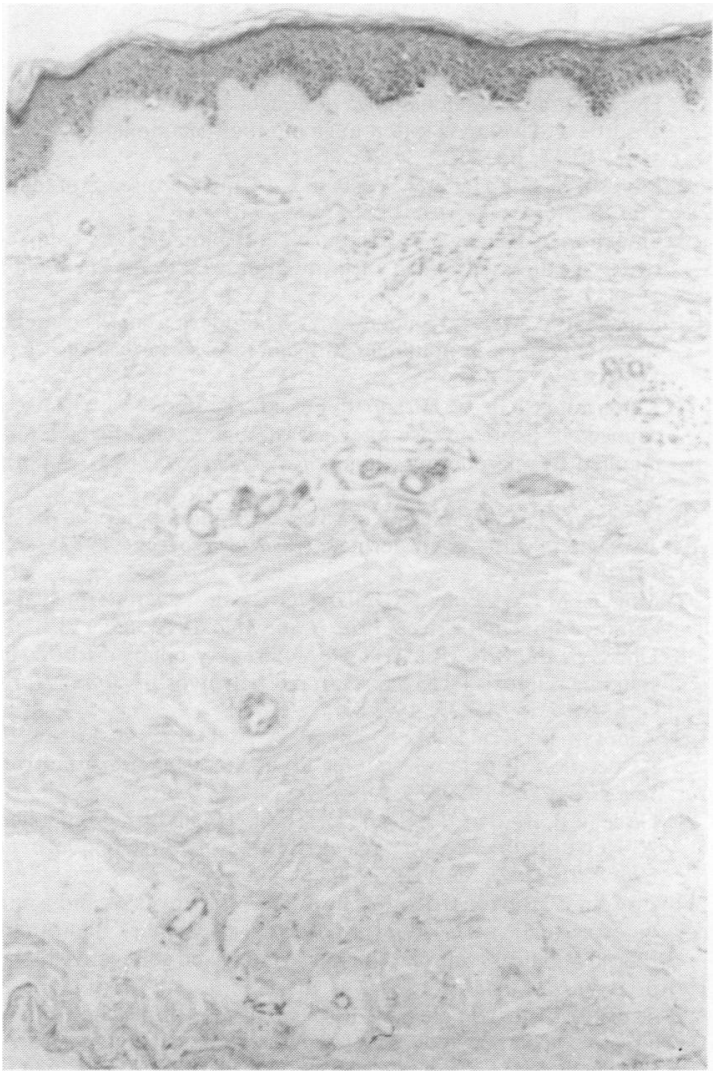

Fig. 2 Skin biopsy obtained from the forearm showing marked thickening of the dermis as a result of deposition of dense collagenous connective tissue. (Haematoxylin and eosin, $\times 37$ ).

(Fig. 2). Percutaneous liver biopsy showed changes typical of primary biliary cirrhosis (PBC) (Figs. 3a, b).

\section{Discussion}

In 1964 Miyoshi et al. ${ }^{1}$ reported the case of a Japanese woman who developed autoimmune disease-like symptoms following an augmentation injection of foreign substances. In that report they speculated that paraffin, silicone, or related substances injected into the breasts might have had adjuvant effects in the development of the disease. ${ }^{2}$ Since then more than 30 patients with autoimmune disease-like syndromes and some patients who developed classic collagen diseases have been reported. These cases have included systemic lupus ery thematosus, ${ }^{3}$ rheumatoid arthritis, ${ }^{3}$ scleroderma,${ }^{4}$ and mixed connective tissue

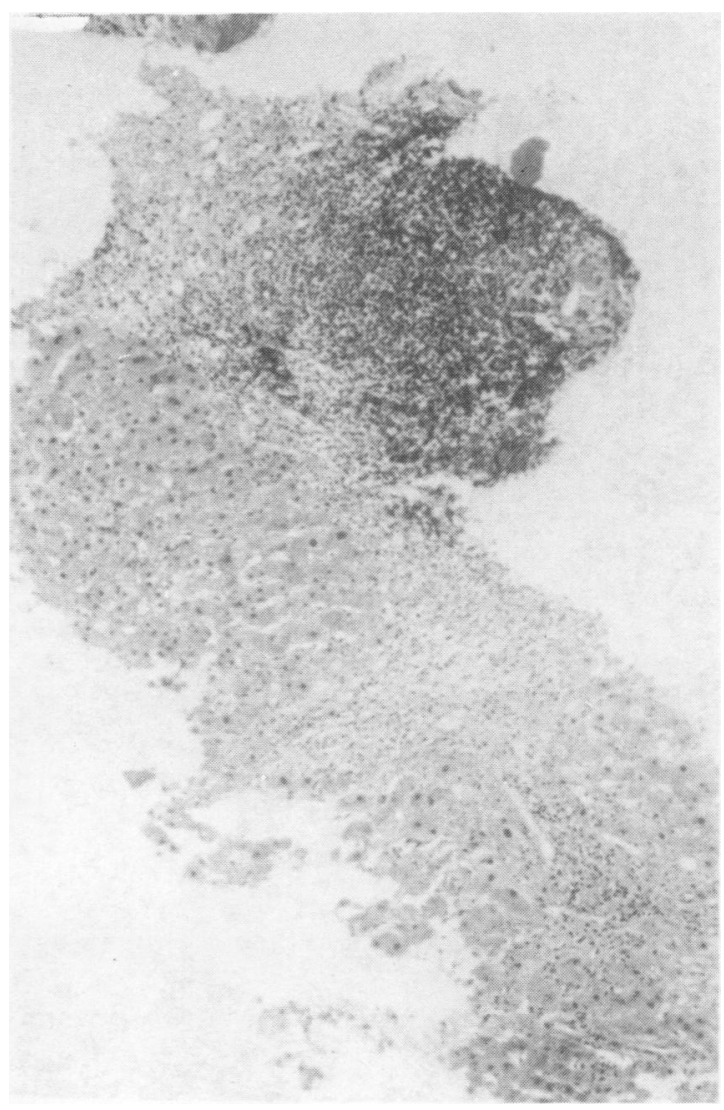

Fig. 3 (a) Liver section obtained by percutaneous needle biopsy showing severe inflammatory reaction in the portal area. ( $H$ and $E, \times 37)$.

disease. ${ }^{5}$ No cases have been reported previously in which primary biliary cirrhosis (PBC) developed after this type of injection.

In 1972 O'Brien et al. ${ }^{6}$ reported the first case in which PBC and diffuse scleroderma coexisted. In the last 10 years seven additional cases with such a combination have been reported..$^{7-12}$

The pathogenesis of the association of scleroderma and $\mathrm{PBC}$ remains unclear. But several common serological abnormalities-antinuclear, antithyroid, and antimitochondrial antibodies-occur in both entities. Recent reports indicate that susceptibility to some autoimmune disorders is related to immunogenetic patterns. In Caucasians scleroderma and PBC have been shown to be related to HLA-DR ${ }^{13}$ and DR ${ }^{14}{ }^{15}$ respectively. In the Japanese HLA-Bw61 or DRw $8^{16}$ and DR2 ${ }^{17}$ or DR9 ${ }^{18}$ have been proposed as such genetic associations in 


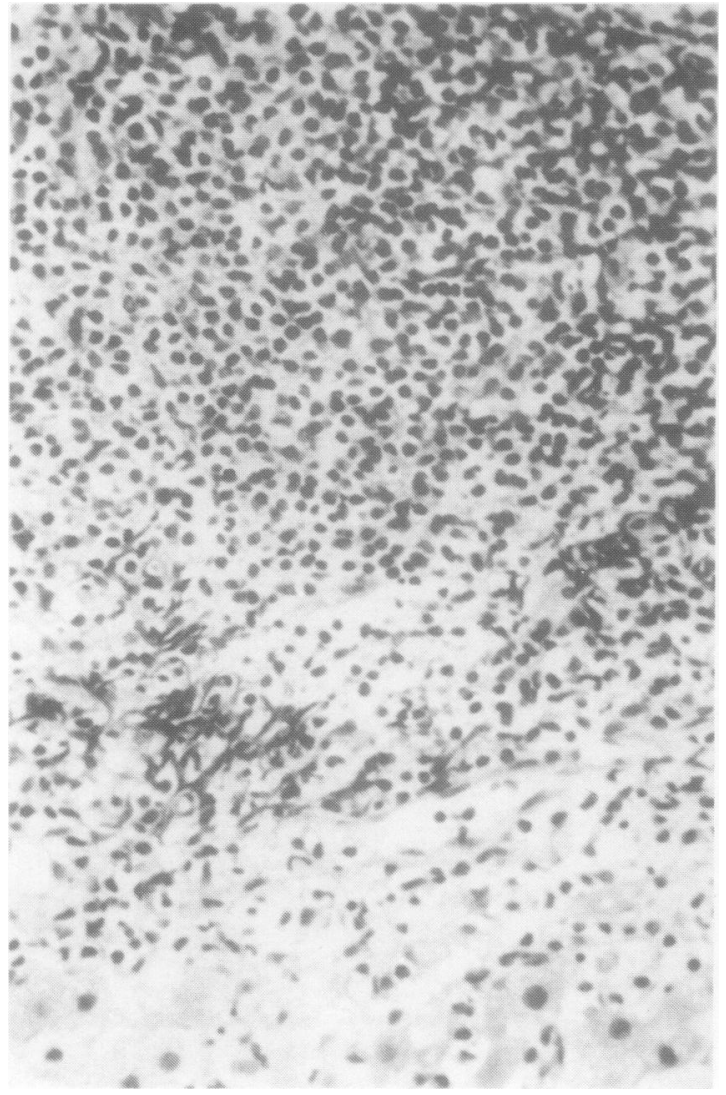

Fig. 3 (b) Higher magnification of the portal area in Fig. $3 a$ showing in filtration of lymphocytes and plasma cells and absence of interlobular bile ducts. ( $H$ and $E, \times 380)$.

scleroderma and $\mathrm{PBC}$ respectively. This patient had both DR2 and DR9 antigens.

In conclusion, this patient had a genetic predisposition to primary biliary cirrhosis, and the breast augmentation with silicone may have facilitated the development of scleroderma and Sjögren's syndrome.

\section{References}

1 Miyoshi K, Miyamura T, Kobayashi Y, Itakura T, Nishijo K. Hypergammaglobulinemia by prolonged adjuvanticity in men. Disorders developed after augmentation mammaplasty. Jpn Med J 1964; no. 2122: 9-14.

2 Miyoshi K, Shiragami H, Yoshida K. Adjuvant disease of man. Clin Immunol (Tokyo) 1973; 5: 785-94.

3 Shiokawa Y, Kumagai Y, Nishino N. Post mammaplasty connective tissue disease (human adjuvant disease). Rev Int Rheumatol 1978; 7: 225-9.

4 Kumagai Y, Abe C, Shiokawa Y. Scleroderma after cosmetic surgery. Four cases of human adjuvant disease. Arthritis Rheum 1979; 22: 532-7.

5 Kumagai Y, Abe C, Hirano T, Fukuda Y, Shiokawa Y. Mixed connective tissue disease after breast augmentation which terminated in scleroderma kidney. Rhymachi 1981; 21 (Suppl): 171-176.

6 O'Brien S T, Eddy W M, Krawitt E L. Primary biliary cirrhosis associated with scleroderma. Gastroenterology 1972; 62: 118-21

7 Mogan M Y. Primary biliary cirrhosis, scleroderma and keratoconjunctivitis sicca. Proc $R$ Soc Med 1973; 66: 1112.

$8 \mathrm{Uhr}$ G S, Baldwin J L, Arnett F C. Primary biliary cirrhosis in systemic sclerosis (scleroderma) and polymyositis. Johns Hopkins Med J 1974; 135: 191-8.

9 Zilberait D, Krulik M, Audebert A A, Debray J, Darnis F. Association de sclérodermie et de cirrhose biliaire primitive. Sem Hop Paris 1979; 55: 1473-8.

10 Godeau P, Bletry O, Zafrane E, Brion N, Chauveinc L, Galian A. Hepatopathies chroniques et sclérodermie systémique. Sem Hop Paris 1980; 56: 1895-900.

11 Epstein O, Burroughs A K, Sherlock S. Polymyositis and acute onset systemic sclerosis in a patient with primary biliary cirrhosis: a clinical syndrome similar to the mixed connective tissue disease. J $R$ Soc Med 1981; 74: 456-8.

12 Tanaka $E$, Imai $T$, Nosawa $K$, et al. A case of primary biliary cirrhosis complicated with progressive systemic sclerosis. Sjögren's syndrome and Hashimoto's thyroiditis. Hepatology (Tokyo) 1981; 105: 1473-9.

13 Gladman D D, Keystone E C, Baron M, Lee P, Cane D, Mervert H. Increased frequency of HLA-DR5 in scleroderma. Arthritis Rheum 1981; 24: 854-6.

14 Galbraith R M, Eddleston A L W F, Smith M G M, et al. Histocompatibility antigens in active chronic hepatitis and primary biliary cirrhosis. $\mathrm{Br} \mathrm{Med} \mathrm{J} \mathrm{1974;} \mathrm{iii:} \mathrm{604-5.}$

15 Ercilla G, Pares A, Arriaga F, et al. Primary biliary cirrhosis associated with HLA DRw3. Tissue Antigens 1979; 14: 449-52.

16 Moroi Y, Takeuchi A, Chihara T, et al. Study on antinuclear antibody and HLA antigens in scleroderma. Ryumachi 1982;22: 516-7.

17 Miyamori $\mathrm{H}$, Kumagai M, Tanaka N, et al. HLA antigens in primary biliary cirrhosis and autoimmune liver disease. Hepatology (Tokyo) 1981; 22: 1761.

18 Daiguji $Y$, Izumi $N$, Hattori $M$, et al. Clustering of seroimmunologic abnormalities including anti-mitochondrial antibody observed in siblings of patient with primary biliary cirrhosis. Nippon Naika Gakkai Zasshi 1983; 72: 594-9. 